\title{
One-pot efficient green synthesis of 1,4-dihydro-quinoxaline-2,3-dione derivatives
}

\author{
HARJYOTI THAKURIA and GOPAL DAS* \\ Department of Chemistry, Indian Institute of Technology Guwahati, Guwahati 781039 \\ e-mail: gdas@iitg.ernet.in
}

MS received 22 May 2006; revised 28 August 2006

\begin{abstract}
An efficient synthesis of the potential pharmacophore 1,4-dihydro-quinoxaline-2,3-dione (1) has been achieved in a one-pot reaction at room temperature from substituted $o$-phenylene diamine and oxalic acid under solvent-free conditions by a simple grinding method with unsurpassed atom economy. Thermal and powder X-ray diffraction analysis was carried out for some hydrated crystals.
\end{abstract}

Keywords. Green chemistry; quinoxaline; $o$-phenylene diamine; oxalic acid; grinding; atom economy.

\section{Introduction}

Quinoxaline-diones and their derivatives are important members of heterocyclic compounds that are widely applied in many fields, as curatorial intermediates, bacteriocides and insecticides. ${ }^{1}$ It is one of the main classes of known antagonists of amino propanoic acid (AMPA). The quinoxaline moiety is also present in peptide antibiotics. Due to their wide range of applications, these compounds have received a great deal of attention in connection with their synthesis. One-pot efficient synthesis of quinoxaline-diones derivatives may permit the development of novel therapies for the treatment of epilepsy, pain and other neurodegenerative disorders. ${ }^{1,2}$ Many synthetic methods for these heterocyclic compounds have been reported which include the use of catalysts and/or some special techniques. ${ }^{2}$ However, many of these methods are associated with several shortcomings such as long reaction times, expensive reagents, harsh conditions, low-product yields, occurrence of several side products and difficulties in recovery and reusability of the catalysts. As part of our research on the development of newer and cleaner processes for organic transformations, ${ }^{3}$ our attention was drawn to the synthesis of these potential pharmacophore 1,4-dihydro-quinoxaline-2,3-dione (1) derivatives. Herein, we report simple solid phase grinding of the two reactants at room temperature in

*For correspondence an open atmosphere to get the product in good yield (scheme 1).

\section{Experimental}

\subsection{Materials}

The compounds, benzene-1,2-diamine, 4-nitro-benzene-1,2-diamine, 4-chloro-benzene-1,2-diamine, 4methyl-benzene-1,2-diamine, 4-propyl-benzene-1,2diamine, 4-phenyl-benzene-1,2-diamine and 4,5dichloro-benzene-1,2-diamine were acquired from Aldrich and used as received. All solvents were obtained from S D Fine Chemicals.

\subsection{Physical measurements}

${ }^{1} \mathrm{H}$ NMR and ${ }^{13} \mathrm{C}$ NMR were recorded on a Varian FT-400 MHz instrument. IR spectra were recorded on a Perkin-Elmer Spectrum One FT-IR spectrometer with $\mathrm{KBr}$ disks in the range $4000-400 \mathrm{~cm}^{-1}$. Thermo gravimetric analyses (TGA) of the compounds were performed using an SDTA 851e TGA thermal analyzer (Mettler Toledo) with a heating rate of $2^{\circ} \mathrm{C}$ per<smiles>Nc1cc(I)c(I)cc1N</smiles>

Scheme 1. 
min in an $\mathrm{N}_{2}$ atmosphere. PXRD data were recorded with a Seifert powder X-ray diffractometer (XRD 3003TT) with $\mathrm{CuK}_{\alpha}$ source $(\lambda=1.54 \AA)$ on glass surface with an air-dried sample. Elemental analyses were done using Carlo-Erba 1108 and Perkin-Elmer series II 2400 instruments.

\subsection{General synthesis of quinoxaline derivatives}

This solvent-free method has an operationally simple procedure. In a typical experiment, a mixture of oxalic acid dihydrate $(1 \mathrm{mmol}, 0.126 \mathrm{~g})$ and $o$-phenylene diamine $(1 \mathrm{mmol}, 0 \cdot 108 \mathrm{~g})$ was thoroughly ground with a pestle in a mortar at room temperature in an open atmosphere until the mixture turned into a melt. The mixture continued to be ground occasionally for different periods as indicated in table 1 . Then the melt was crystallized from water or water/ ethanol $(1: 1)$ mixture to get the pure products. Details of the substrates used, products obtained, reaction times and yields are given in table 1 .

\subsection{Spectral data for the products}

2.4a 1,4-Dihydro-quinoxaline-2,3-dione ${ }^{1} H$ NMR $\left(400 \mathrm{MHz}, \mathrm{DMSO}-d_{6}\right): \delta=6.91(\mathrm{~m}, 2 \mathrm{H}), 7.02(\mathrm{~m}$, $2 \mathrm{H}), 9.43(s, 2 \mathrm{H}) ;{ }^{13} \mathrm{C}$ NMR (100 MHz, DMSO- $\left.d_{6}\right)$ : $\delta=118.6,122 \cdot 4,127 \cdot 3,156 \cdot 5$; Analysis - Calcd. for $\mathrm{C}_{8} \mathrm{H}_{6} \mathrm{~N}_{2} \mathrm{O}_{2}$ : C 59.26, H 3.73, N 17.28\%. Found: C 58.98, H 3.75, N 17.30\%; MS $(\mathrm{m} / \mathrm{z}): 162 \cdot 0\left(M^{+}\right)$.

2.4b 6-Nitro-1,4-dihydro-quinoxaline-2,3-dione ${ }^{1} \mathrm{H}$ NMR (400 MHz, DMSO-d $\left.d_{6}\right): \delta=7.57(d, 1 \mathrm{H}), 7.95$ $(d, 1 \mathrm{H}), 8.43(s, 1 \mathrm{H}), 9.73(s, 2 \mathrm{H}) ;{ }^{13} \mathrm{C}$ NMR $\left(100 \mathrm{MHz}, \quad \mathrm{DMSO}-d_{6}\right): \quad \delta=113 \cdot 7, \quad 117 \cdot 4,120 \cdot 3$, $129.5,133.7,142.2,157.5$; Analysis - Calcd. for $\mathrm{C}_{8} \mathrm{H}_{5} \mathrm{~N}_{3} \mathrm{O}_{4}$ : C $46 \cdot 39, \mathrm{H} 2 \cdot 43, \mathrm{~N} 20 \cdot 29 \%$. Found: $\mathrm{C}$ 46.35, H 2.41, N 20.26\%; MS ( $/ / z): 207 \cdot 0\left(M^{+}\right)$.

Table 1. Green synthesis of quinoxaline derivatives.

\begin{tabular}{lcccc}
\hline Entry & $\mathrm{A}$ & $\mathrm{B}$ & Time $(\mathrm{h})$ & ${\text { Yield }(\%)^{\mathrm{a}}}^{\mathrm{a}}$ \\
\hline $\mathrm{a}$ & $\mathrm{H}$ & $\mathrm{H}$ & 0.5 & 98 \\
$\mathrm{~b}$ & $\mathrm{H}$ & $\mathrm{NO}_{2}$ & 3 & 82 \\
$\mathrm{c}$ & $\mathrm{H}$ & $\mathrm{Cl}$ & 2 & 87 \\
$\mathrm{~d}$ & $\mathrm{H}$ & $\mathrm{Me}$ & 1 & 95 \\
$\mathrm{e}$ & $\mathrm{H}$ & $n-\mathrm{Pr}$ & 1 & 95 \\
$\mathrm{f}$ & $\mathrm{H}$ & $\mathrm{Ph}$ & $0 \cdot 5$ & 96 \\
$\mathrm{~g}$ & $\mathrm{Cl}$ & $\mathrm{Cl}$ & 5 & 76 \\
\hline
\end{tabular}

${ }^{\mathrm{a}}$ Yields of the isolated product 2.4c 6-Chloro-1,4-dihydro-quinoxaline-2,3-dione ${ }^{1} H$ NMR $\left(400 \mathrm{MHz}, D M S O-d_{6}\right): \delta=6.91(d, 1 \mathrm{H}), 7.32$ $(d, 1 \mathrm{H}), 7.86(s, 1 \mathrm{H}) ; 9.43 \quad(s, 2 \mathrm{H}){ }^{13} \mathrm{C}$ NMR $\left(100 \mathrm{MHz}, \quad \mathrm{DMSO}-d_{6}\right): \delta=119 \cdot 0,121 \cdot 3,122 \cdot 7$, $125 \cdot 3,129 \cdot 6,132 \cdot 5,160 \cdot 2$; Analysis - Calcd. for $\mathrm{C}_{8} \mathrm{H}_{5} \mathrm{ClN}_{2} \mathrm{O}_{2}$ : C $48 \cdot 88, \mathrm{H} 2 \cdot 56, \mathrm{~N} 14 \cdot 25 \%$. Found: $\mathrm{C}$ 48.87, H 2.54, N 14.23\%; MS ( $\mathrm{m} / \mathrm{z}): 196 \cdot 5\left(M^{+}\right)$.

2.4d 6-Methyl-1,4-dihydro-quinoxaline-2,3-dione ${ }^{1} \mathrm{H}$ NMR (400 MHz, DMSO-d $): \delta=2 \cdot 21(s, 3 \mathrm{H}), 6 \cdot 78$ $(d, 1 \mathrm{H}), 7 \cdot 22(s, 1 \mathrm{H}), 7 \cdot 51(d, 1 \mathrm{H}), 10 \cdot 11(m, 2 \mathrm{H})$; ${ }^{13} \mathrm{C}$ NMR $\left(100 \mathrm{MHz}\right.$, DMSO- $\left.d_{6}\right): \delta=21 \cdot 2,117 \cdot 5$, $119 \cdot 3,123 \cdot 7,127 \cdot 3,131 \cdot 2,135 \cdot 7,156 \cdot 5$; Analysis Calcd. for $\mathrm{C}_{9} \mathrm{H}_{8} \mathrm{~N}_{2} \mathrm{O}_{2}$ : C 61.36, H 4.58, N 15.90\%. Found: C 61.33, H 4.51, N 16.01\%; MS (m/z): 176.0 $\left(M^{+}\right)$.

2.4e 6-Propyl-1,4-dihydro-quinoxaline-2,3-dione ${ }^{1} \mathrm{H}$ NMR (400 MHz, DMSO-d $\left.d_{6}\right): \delta=0.89(t, 3 \mathrm{H}), 1.54$ $(m, 2 \mathrm{H}), 2.55(t, 2 \mathrm{H}), 6.71(d, 1 \mathrm{H}), 7.32(s, 1 \mathrm{H})$, $7.62(d, 1 \mathrm{H}), 9.53(s, 2 \mathrm{H}) ;{ }^{13} \mathrm{C}$ NMR $(100 \mathrm{MHz}$, DMSO- $\left.d_{6}\right): \quad \delta=13.5,24.6,37.9, \quad 120 \cdot 5,122 \cdot 3$, $123 \cdot 5,126 \cdot 7,131 \cdot 2,135 \cdot 1,159 \cdot 4$; Analysis - Calcd. for $\mathrm{C}_{11} \mathrm{H}_{12} \mathrm{~N}_{2} \mathrm{O}_{2}$ : C 64.69, H 5.92, N 13.72\%. Found: C 64.67, H 5.91, N 13.70\%; MS (m/z): $204.0\left(M^{+}\right)$.

$2.4 \mathrm{f}$ 6-Phenyl-1,4-dihydro-quinoxaline-2,3-dione ${ }^{1} H$ NMR $\left(400 \mathrm{MHz}, \mathrm{DMSO}-d_{6}\right): \delta=7 \cdot 21-7 \cdot 37(\mathrm{~m}, 4 \mathrm{H})$, $7.48(d, 2 \mathrm{H}), 7.68(d, 1 \mathrm{H}), 7.91(s, 1 \mathrm{H}), 9.27(s, 2 \mathrm{H})$; ${ }^{13} \mathrm{C}$ NMR $\left(100 \mathrm{MHz}, \mathrm{DMSO}-d_{6}\right): \delta=118.6,121.4$, $123 \cdot 2,127 \cdot 3,129 \cdot 0,131 \cdot 2,132 \cdot 5,136 \cdot 4,159 \cdot 3$; Analysis - Calcd. for $\mathrm{C}_{14} \mathrm{H}_{10} \mathrm{~N}_{2} \mathrm{O}_{2}: \mathrm{C} 70 \cdot 58, \mathrm{H} 4 \cdot 23$, N 11.76\%. Found: C 70.57, H 4.21, N 11.75\%; MS $(\mathrm{m} / \mathrm{z}): 238 \cdot 0\left(M^{+}\right)$.

2.4g 6,7-Dichloro-1,4-dihydro-quinoxaline-2,3-dione ${ }^{1} \mathrm{H} N M R\left(400 \mathrm{MHz}, D M S O-d_{6}\right): \delta=7.62(s, 2 \mathrm{H})$, $9.79(s, 2 \mathrm{H}) ;{ }^{13} \mathrm{C}$ NMR (100 MHz, DMSO- $\left.d_{6}\right)$ : $\delta=121 \cdot 6,128 \cdot 4,131 \cdot 3,163 \cdot 5$; Analysis - Calcd. for $\mathrm{C}_{8} \mathrm{H}_{4} \mathrm{Cl}_{2} \mathrm{~N}_{2} \mathrm{O}_{2}$ : C $41 \cdot 59, \mathrm{H} 1 \cdot 75, \mathrm{~N} 12 \cdot 13 \%$. Found: $\mathrm{C}$ 41.57, H 1.74, N 12.11\%; MS ( $/ / z): 230 \cdot 0\left(M^{+}\right)$.

\section{Results and discussion}

In view of the problems encountered in quinoxaline synthesis, a relatively more versatile yet simplified procedure was perceived. Our arguments have been that solid phase grinding would lead to an instantaneous condensation to afford quinoxalines without the use of any solvent or catalyst. The strategy worked well, affording the desired products in respectable 
yields (table 1). The present reactions have been relatively faster, as anticipated, compared to those in conventional solution phase synthesis. It is necessary to mention that in all cases the conversion was never $100 \%$. Small amounts of starting materials were recovered after each reaction. A wide range of $o$-phenylene diamine derivatives were screened in order to ascertain the scope of the present reaction protocol and these results are summarized in table 1. Presence of electron-withdrawing groups in diamine starting materials gave lower yields with longer reaction times. However, the quinoxaline derivative are formed in good to very good yields.

Compounds 1a and 1d both crystallize from water/ EtOH $(1: 1)$ mixture in triclinic space group. These molecules contain two water and $1 / 2$ water molecules of crystallization respectively in the crystal structure, which corresponds to the reported data. ${ }^{4}$ We also got the crystal of only 1a without any water of crystallization, when crystallized from $\mathrm{MeOH} / \mathrm{EtOAc}$ mixture, as reported earlier. ${ }^{5}$ In compound 1a, the extensive hydrogen bonding interactions between the organic framework and the water cluster are strong enough. Thermo gravimetric analysis with a $10.2367 \mathrm{mg}$ of sample in $\mathrm{N}_{2}$ atmosphere shows the sequential removal of the two molecules of water of crystallization at a temperature $>100^{\circ} \mathrm{C}$.

The $9.86 \%$ weight loss in the range $155-165^{\circ} \mathrm{C}$ corresponding to one water molecule (calculated $9.09 \%$ ) and $13.42 \%$ weight loss at in the range 165

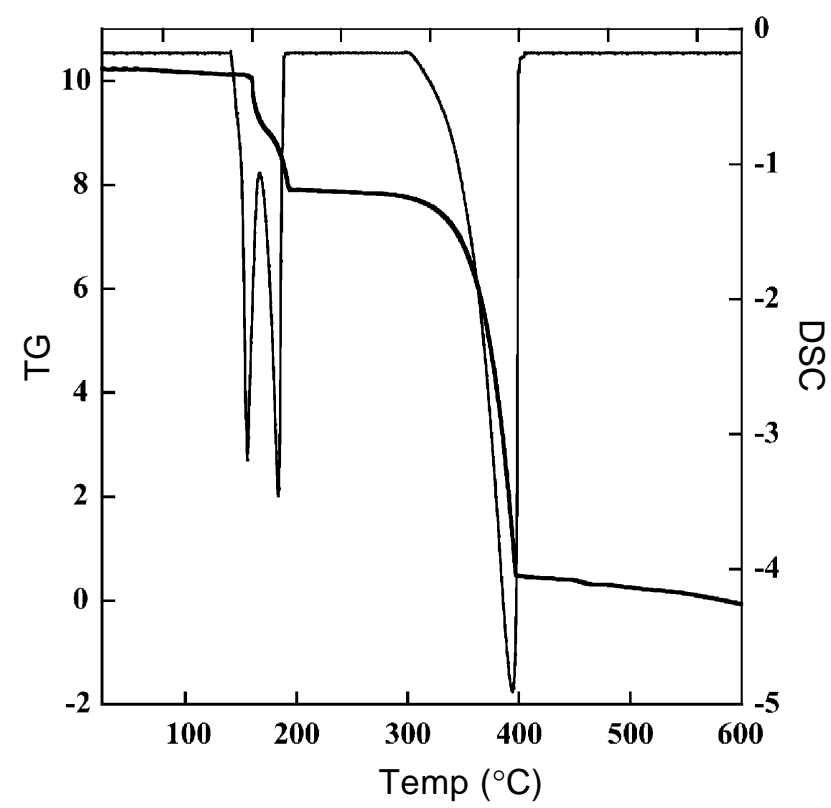

Figure 1. TGA-DSC plot of compound 1a. $185^{\circ} \mathrm{C}$ corresponding to another water molecule (calculated $10.00 \%$ ) respectively, which is in good agreement with the X-ray crystal structure of 1a. ${ }^{4}$ Temperature required to remove both the water molecules from the crystal is higher compared to that previously reported $D_{2 h}$ symmetric tetrameric water cluster. ${ }^{6}$ Complete decomposition is achieved at $\sim 390^{\circ} \mathrm{C}$ (figure 1 ). The DSC measurement shows that the dehydration endotherm has two peaks $\left(160^{\circ} \mathrm{C}\right.$ and $180^{\circ} \mathrm{C}$ ) indicating that the two sets of water molecules are in different environments in the solid state, which is again consistent with the X-ray crystal structure (figure 1). The total molar enthalpy is 20 and $16 \mathrm{~kJ}$ per water molecule respectively. These values correspond to $5 \mathrm{~kJ}$ per H-bond, which are in good agreement with the strength of a hydrogen bond. ${ }^{7}$ Compound 1d also shows a TGA-DSC pattern similar to that of 1a. It shows only one dehydration endotherm at $190^{\circ} \mathrm{C}$ and complete decomposition at $\sim 430^{\circ} \mathrm{C}$.

The FT-IR spectrum of compound 1a shows a broad band centred on $3400 \mathrm{~cm}^{-1}$ due to the presence of water molecules that vanishes when the compound is heated under vacuum $(0.1 \mathrm{~mm})$ at $250^{\circ} \mathrm{C}$ for $6 \mathrm{~h}$ (figure 2). When the peaks correspond to the amide, linkages remain intact.

Powder X-ray diffraction patterns of 1a show significant changes in the peak positions as well as in-

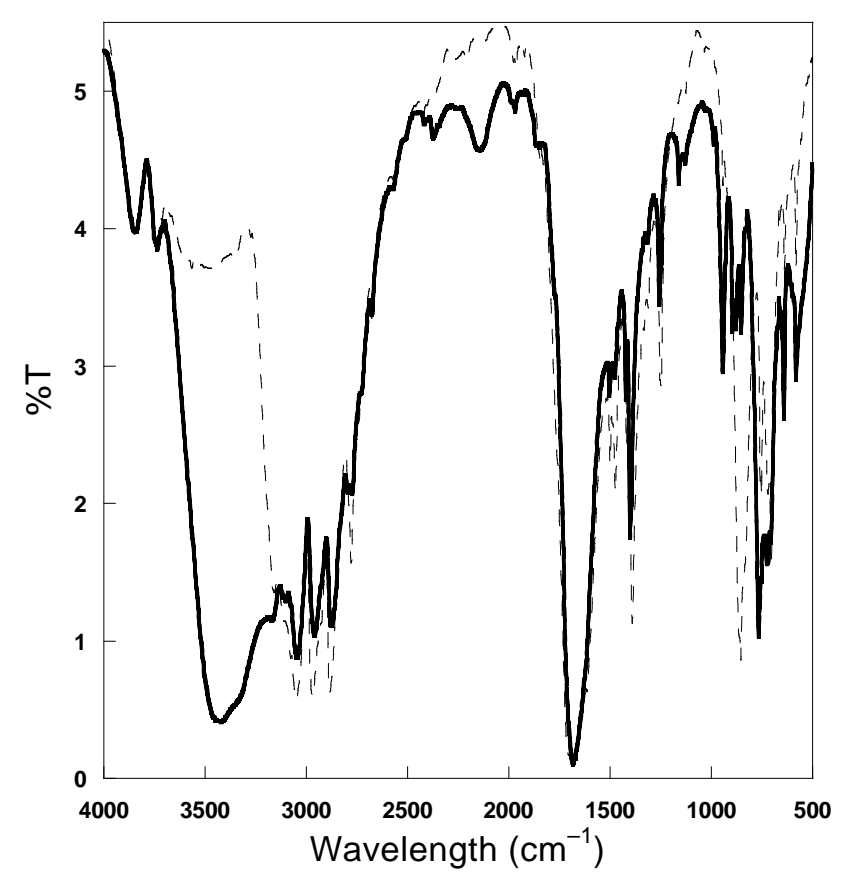

Figure 2. FT-IR spectra of 1a (- before heating and --- after heating). 


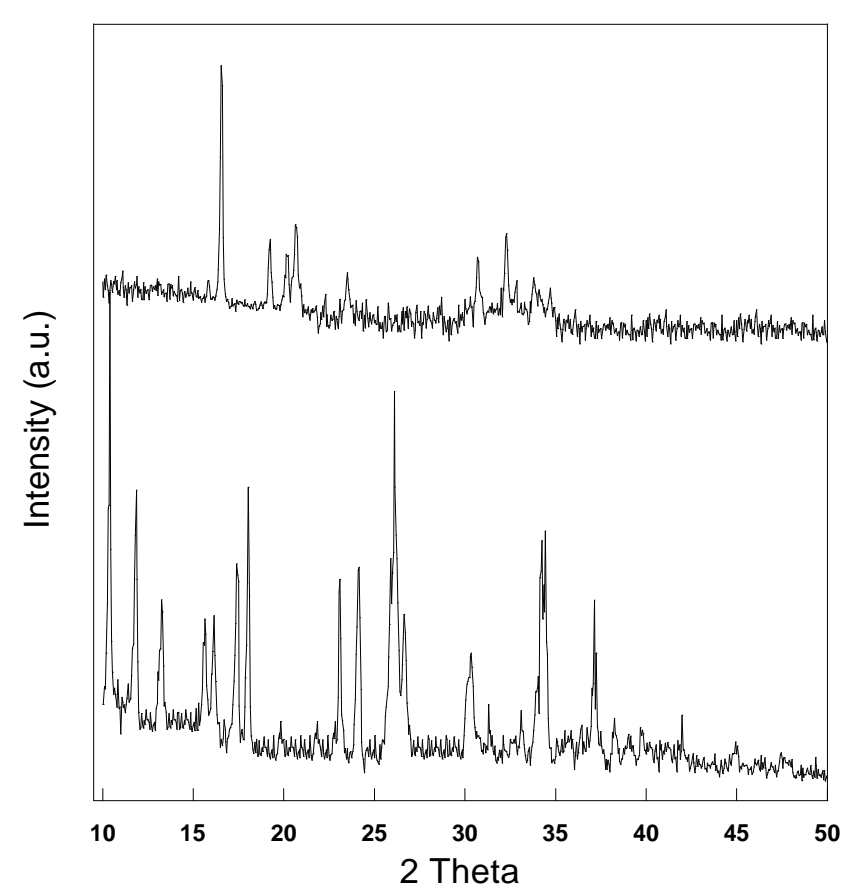

Figure 3. Powder XRD pattern of compound 1a. Before water removal (bottom) and after water removal (top).

tensities before and after water removal (figure 3), which also match well with the simulated pattern. Similar powder diffraction and FT-IR results are observed for compound $\mathbf{1 d}$ also.

\section{Conclusion}

In conclusion, we have developed a simple, solventfree, very efficient protocol for the synthesis of qui- noxaline derivatives without the intervention of any catalyst for the first time. We have done the thermal analysis of the hydrated crystals of the two derivatives (1a and 1d). We also carried out the powder Xray diffraction and FT-IR analysis of the hydrated as well as the dehydrated crystals to prove the role of water of crystallization in stabilizing the overall solid state structural network of these molecules.

\section{Acknowledgement}

GD thanks the Council of Scientific and Industrial Research, New Delhi for financial support.

\section{References}

1. Moloney M G 2002 Nat. Prod. Rep. 19597

2. (a) Jian F F and Zhao P S 2004 J. Mol. Struct. 705 133; (b) Cheon H G, Lee C M, Kimb B T and Hwangb K J 2004 Bioorg. Med. Chem. Lett. 14 2661; (c) Kaupp G and Naimi-Jamal M R 2002 Eur. J. Org. Chem. 8 1368; (d) Wang L, Liu J, Tian H and Qian C 2004 Synth. Commun. 341349

3. Thakuria H T, Pramanik A, Borah B M and Das G 2006 Tetrahedron Lett. 473135

4. Oxtoby N S, Blake A J, Champness N R and Wilson C 2005 Chem. Eur. J. 114643

5. Jian F F and Zhao P S 2004 J. Mol. Struct. 705133

6. Tao J, Ma Z J, Huang R B and Zheng L S 2004 Inorg. Chem. 436133

7. (a) Schneider S 1991 Reviews in computational chemistry (New York: VCH) vol. 2; (b) Cheruzel L E, Pometun M S, Cecil M R, Mashuta M S, Wittebort R J and Buchanan R M 2003 Angew. Chem. Int. Ed. 42 5452 